\title{
Electrical and thermal conductivity of ethylene vinyl acetate composite with graphene and carbon black filler
}

\author{
Sohrab Azizi ${ }^{1}$, Eric David ${ }^{1}$, Michel F. Fréchette ${ }^{1}$, Phuong Nguyen-Tri ${ }^{1,2}$, Claudiane Ouellet- \\ Plamondon $^{1^{*}}$ \\ ${ }^{1}$ École de technologie supérieure (Université du Québec), Montréal, QC, Canada \\ ${ }^{2}$ Department of Chemistry, Montreal University, Montréal, QC, Canada
}

\begin{abstract}
Ethylene vinyl acetate (EVA) composites, including two different carbonaceous conductive fillers, carbon black (CB) and commercially available graphene $(\mathrm{G})$, were fabricated by solventcasting and melt compounding methods. The effect of additives and process conditions on electrical and thermal properties of composites was investigated. The dielectric responses of EVA composites were characterized by a percolation threshold of $15 \mathrm{wt} \%$ for EVA/G prepared by solvent-casting. However, as the EVA/G15\% was also subsequently extruded, the applied shear stress induced by extrusion caused deterioration of the electrical network and reduced the composite's electrical conductivity. A percolating network was found for the EVA composites containing $\mathrm{CB}$ at around 5-7 wt \% with 10 orders of magnitude increase in electrical conductivity with respect to the neat EVA. The thermal conductivity of EVA/CB7\% and EVA/G15\% increased 16 and $22 \%$ respectively, in comparison to the neat EVA. Both additives increased the electrical and thermal conductivity of composites to be appropriate as jackets for high-voltage cables.
\end{abstract}

Keywords: Electrical properties; Thermal conductivity; Ethylene vinyl acetate; Carbon black; Graphene.

\footnotetext{
* Corresponding author: Department of construction engineering, École de technologie supérieure (ÉTS), Université du Québec, 1100 Notre-Dame St W, Montréal, QC H3C 1K3 Canada. Email address : Claudiane.Ouellet-Plamondon@etsmtl.ca 


\section{Introduction}

Ethylene vinyl acetate (EVA), a random copolymer, is made from ethylene and vinyl acetate monomer via continuous bulk polymerization or an emulsion process [1]. The vinyl acetate (VA) content in EVA copolymer ranges from 1-50 wt\% [2], depending on the desired mechanical and physical properties. The inclusion of higher VA content in EVA decreases the average molecular weight of EVA copolymer, which consequently changes the copolymer properties. For instance, the stiffness modulus, surface hardness, crystallinity, melting point and softening point of the EVA polymer are reduced due to the higher VA content [1,3]. Although the increase in VA content undermines some properties, it leads to several improvements for electrical applications such as high dielectric strength, high volume resistivity against low and moderate voltages, and suitable compatibility with polar polymers for blending. [1, 4-7]

Ethylene vinyl acetate (EVA) and its conductive composites are widely used in electrical cables [8], self-regulating heaters and sensors $[9,10]$, electronic devices in the automotive industry [11, 12], and electromagnetic interference shielding (EMI) applications [1, 13]. The use of neat EVA copolymer without additives features some drawbacks involving low electrical and thermal conductivity and sometimes inadequate mechanical properties. Accordingly, the combination of the pure EVA with conductive additives such as graphene-based materials can serve to increase the electrical conductivity. An improvement in the electrical conductivity of EVA was reported by addition of 4 and $8 \mathrm{wt} \%$ of reduced graphene oxide and polyaniline, respectively [14]. Also, the thermal stability and electrical conductivity were found to be improved by $42{ }^{\circ} \mathrm{C}$ and 10 orders of magnitude, respectively, with the addition of $8 \mathrm{wt} \%$ functionalized graphene additive to the pure EVA [8]. The effect of VA content in EVA on graphene dispersion and the percolation network in EVA/G nanocomposite indicated that the lowest percolation threshold is found for VA content at approximately $20 \mathrm{wt} \%$ [15]. Furthermore, according to Yang et al., the electrical conductivity of EVA-based nanocomposite including carbonaceous filler is dependent on the VA content, as well as the nano-additive concentration in the vicinity of the percolation threshold [16].

The particle shape, the morphology of additive, the inherent electrical conductivity of the nanofiller as well as the aspect ratio of conducting fillers can all significantly influence the final electrical and thermal conductivity of nanocomposites [17]. Thus, it is relevant to study the effect of several carbonaceous nanofillers with different shapes and physical properties. Moreover, the 
fabrication method and the incorporation of functionalizing or compatibilizer agents can play a dominant role in determining the properties of the fabricated composite [18]. Therefore, in this study, more or less spherical and highly conductive CB filler has been selected as reference filler for comparison with a commercially available graphene.

Oxygenated groups such as hydroxyl or esteric groups exist more or less in carbonaceous derivatives such as graphene-like materials [19], and are expected to be fairly compatible with the polar part (VA part) of the EVA copolymer, Therefore, the compatibility of the graphene-like and carbon black plays a significant role in composite properties. However, the influence of fabrication method is often dominant over the chemical affinity and the dispersion of the particles in impacting the final properties of composites [20-24]. Hence, the effect of melt compounding after solventcasting on the electrical, thermal and mechanical properties of EVA/G composites at percolation threshold is investigated in this study.

To the best of our knowledge, most of the previous studies on EVA and the corresponding nanocomposites were focused on the effect of VA content, interactions of additives with EVA matrix, the blending of EVA with different polymers, or using compatibilizers, as well as the surface modification of the particles [3, 6, 20, 25-28]. Few studies investigate the dominant influence of the compounding procedure on the particles' reorientation and the resulting properties. In this study, the EVA matrix was blended with two conductive additives, CB and graphene, via solvent-casting technique. One of the samples featuring a critical filler concentration was further processed by extrusion. The thermal properties and the morphology of the composites, as well as the low field dielectric response, were investigated.

\section{Experimental}

\subsection{Materials}

EVA copolymer was provided by Repsol Company with $28 \mathrm{wt} \%$ VA content and a density of $0.950 \mathrm{~g} / \mathrm{cm}^{3}$. The commercially available graphene filler (heXo-GV20) was obtained from NanoXplore Inc (Montreal, Canada). This is a versatile and large-scale graphene product with nanoplatelets with an average thickness of $20 \mathrm{~nm}$ (40 layers) and a flake size of $50 \mu \mathrm{m}$. The spheroid-shape CB filler (VXC500 grade, CABOT, USA) with an apparent density of 1.7-1.9 $\mathrm{g} / \mathrm{cm}^{3}$ at $20{ }^{\circ} \mathrm{C}$ is suggested as a high electrical conductivity additive with $0.05 \mathrm{wt} \%$ sulfur content 
and $16.7 \mathrm{ppm}$ total ionic. The toluene solvent was purchased from Sigma-Aldrich with $99.5 \%$ purity. All the materials were used as received.

\subsection{Sample fabrication}

The sample fabrication steps are schematically shown in Figure 1. Briefly, the labeled composites with different filler concentrations (Table I) were fabricated via solvent-casting as well as melt compounding. The pure EVA was dissolved in toluene for $30 \mathrm{~min}$ by stirring at $100{ }^{\circ} \mathrm{C}$ and $600 \mathrm{rpm}$. The additives were suspended in toluene with the same fabrication conditions. Both dissolved and suspended solutions were then mixed together and again stirred at $600 \mathrm{rpm}$ and 100 ${ }^{\circ} \mathrm{C}$ for $30 \mathrm{~min}$. Afterwards, the obtained dissolved samples were cast on aluminum foil and dried at room temperature in a fume hood until the remained weight became constant. One of the samples was further compounded in a co-rotating screw mini-extruder (HAAKE MiniLab II) for 5 min of extrusion-circulation time and at $130^{\circ} \mathrm{C}$ in the melting zone. To fabricate the disc-shaped samples, the blends were pressed using a hot press (Accudyne Engineering \& Equipment Company, Los Angles, USA) at $155^{\circ} \mathrm{C}$ and $8 \mathrm{MPa}$.

Table I. Labeled samples with additive content and fabrication method

\begin{tabular}{ccccc}
\hline Sample & EVA $(\mathrm{wt} \%)$ & $\mathrm{G}(\mathrm{wt} \%)$ & $\mathrm{CB}(\mathrm{wt} \%)$ & Fabrication method \\
\hline Pure EVA & 100 & 0 & 0 & Solvent casting \\
EVA/CB5\% & 95 & 0 & 5 & Solvent casting \\
EVA/CB7\% & 93 & 0 & 7 & Solvent casting \\
EVA/CB10\% & 90 & 0 & 10 & Solvent casting \\
EVA/G10\% & 90 & 10 & 0 & Solvent casting \\
EVA/G15\% & 85 & 15 & 0 & Solvent casting \\
EVA/G15\% SM & 85 & 15 & 0 & Solvent casting + Melt mixing \\
\hline
\end{tabular}

\subsection{Characterization}

To investigate the additive dispersion and distribution within the composites, the morphology of the EVA copolymer and EVA composites with $\mathrm{CB}$ and graphene was investigated using a scanning electron microscope (Hitachi, SU-8230 FE-SEM, Japan). The specimens' cross-sections were prepared using a cryogenic microtome and the thin films were subsequently coated with 
approximately $2 \mathrm{~nm}$ of platinum under vacuum using a turbo-pumped sputter coater/carbon coater (Q150T, Guelph, Canada).

The dielectric response of the composites was measured via frequency-domain broadband dielectric spectroscopy (BDS - Novocontrol, Montabaur, Germany) on disk samples with a diameter of $4 \mathrm{~cm}$ and an average thickness of $0.5 \mathrm{~mm}$. Each specimen was mounted between the two brass electrodes forming a typical electrode-dielectric-electrode sandwich. Isothermal scans were performed over a wide range of frequencies ranging from $0.01 \mathrm{~Hz}$ to $10^{5} \mathrm{~Hz}$ at various temperatures under an applied voltage of 3 Vrms. The relative complex permittivity $\varepsilon^{*}$ is expressed in terms of relative real permittivity $\left(\varepsilon^{\prime}\right)$ and relative imaginary permittivity $\left(\varepsilon^{\prime \prime}\right)$ as expressed by: [29]

$$
\varepsilon^{*}(\omega)=\varepsilon^{\prime}(\omega)-\mathrm{i} \varepsilon^{\prime \prime}(\omega)
$$

To investigate the thermal properties of composites such as melting point and the degree of crystallinity ( $\mathrm{X}_{\mathrm{c}} \%$ ), differential scanning calorimetry (DSC) (Q20, TA Instruments, New Castel, USA) was conducted $0-160{ }^{\circ} \mathrm{C}$ with a ramp of $10{ }^{\circ} \mathrm{C} / \mathrm{min}$ under $50 \mathrm{~mL} / \mathrm{min}$ of nitrogen flow rate. The degrees of crystallinity of all samples were calculated according to Equation 2, [30]

$$
X_{c}\left(\%_{\text {Crystallinity }}\right)=\frac{\Delta H_{m}}{\Delta H_{m}^{o} \times\left(1-W_{f}\right)} \times 100 \%
$$

where $\Delta H_{m}$ is the fusion enthalpy of the sample, $\Delta H_{m}^{o}$ is the melting enthalpy of $100 \%$ crystalline polyethylene $(277.1 \mathrm{~J} / \mathrm{g})[27,31]$ and $W_{f}$ is weight fraction of fillers in the composite. The lamellar thickness $(l)$ of the pure EVA and EVA composites with CB and graphene were calculated from the Thomson-Gibbs formula given by Equation 3, [32]

$$
l=\frac{2 \sigma_{e}}{\Delta H_{m}^{\circ}} \times \frac{T_{m}^{\circ}}{T_{m}^{\circ}-T_{m}}
$$

where $T_{m}^{o}$ is the thermodynamic melting point of the infinite perfect crystals $(418.6 \mathrm{~K})$, and $\sigma_{\mathrm{e}}$ is the fold surface energy $\left(90.4 \mathrm{~mJ} / \mathrm{m}^{2}\right)$ [33].

The dynamic mechanical properties of the EVA composites were measured by using a DMA Q800 (TA Instruments, New Castel, USA). A rectangular shaped specimen $(30 \times 7 \mathrm{~mm})$ with a thickness of approximately 0.5 was tested for each sample. The DMA measurements were conducted in tensile mode at a frequency of $1 \mathrm{~Hz}$ and at a temperature range from $-50{ }^{\circ} \mathrm{C}$ to $70{ }^{\circ} \mathrm{C}$ with a ramp of $5{ }^{\circ} \mathrm{C} / \mathrm{min}$. An amplitude of dynamic deformation of $20 \mu \mathrm{m}$ was applied on each 
specimen. The resulting dynamic force was superimposed by static force that was maintained at a value equal to $120 \%$ of the maximum value of the dynamic force throughout the experiment.

The thermal stability of the composite samples was investigated by thermogravimetric analysis (Diamond TG/DTA, PerkinElmer technology, Shelton, CT, USA). The measurements were conducted under a nitrogen atmosphere with a heating ramp of $20{ }^{\circ} \mathrm{C} / \mathrm{min}$ from $200{ }^{\circ} \mathrm{C}$ to $600{ }^{\circ} \mathrm{C}$ and then $10 \mathrm{~min}$ at $600{ }^{\circ} \mathrm{C}$ under air atmosphere. A sample with weight from 10 to $15 \mathrm{mg}$ was selected for each measurement.

The thermal conductivity of composites was measured using a guarded heat flux meter, DTC25 (TA Instruments, New Castel, USA). A $5 \mathrm{~cm}$ in diameter disk sample was mounted between the isothermally cold and hot brass electrodes, applying $137.89 \mathrm{kPa}$ load and $25{ }^{\circ} \mathrm{C}$ differential temperature between the two plates.

\section{Results and discussion}

\subsection{Scanning electron microscopy}

Figure 2 shows the SEM micrographs of the pure EVA and EVA composites with $\mathrm{CB}$ and graphene at 5 and $7 \mathrm{wt} \%$ of CB content. Figures $2 \mathrm{a}$ and $2 \mathrm{~b}$ reflect the morphology of pure EVA at $5 \mathrm{k}$ and $10 \mathrm{k}$ magnification. The CB particles were dispersed throughout the composite randomly, and appeared well distributed at $5 \mathrm{wt} \% \mathrm{CB}$ content (Figures $2 \mathrm{c}$ and $2 \mathrm{~d}$ ). The further addition of $\mathrm{CB}$ to $7 \mathrm{wt} \%$ leads to the onset of connection between the particles, with individual particle size less than $100 \mathrm{~nm}$ and an agglomerate size of 100-300 nm (Figures 2e and 2f). In that case, CB particles are more in contact, forming a continuous carbon network within the composite. This will be further discussed in the following section. Figure 3 exhibits the morphology of EVA composites with 10 and $15 \mathrm{wt} \%$ of graphene content. At $10 \mathrm{wt} \%$ of the graphene, some isolated flake sheets were seen, but most of the individual flakes were found to be piled together due to the intrinsic tendency of graphene to agglomerate (Figure 3a and 3b) [34]. With further addition of graphene, more particle-particle connections and graphene flakes overlapping were found, resulting in some agglomerations at the micrometer scale (Figure 3c and 3d). For the EVA/G15\% compounded by solvent-casting followed by extrusion, the additional extrusion step was found to cause deterioration of the well-connected graphene network, resulting in additional agglomeration of the graphene flakes as some larger agglomerates of $\sim 30-40 \mu \mathrm{m}$ were observed. 


\subsection{Dielectric properties}

Figures $4 \mathrm{a}$ and $4 \mathrm{~b}$ describe the frequency-domain dielectric responses (real and imaginary permittivity, respectively) of the pure EVA and EVA composites with CB and graphene. The inset in Figure $4 \mathrm{a}$ is the modulus of the complex conductivity as a function of frequency. The EVA composites containing CB additive featured a percolation threshold between 5 and $7 \mathrm{wt} \%$. The dielectric response of the EVA/CB7\% was dominated by direct electrical conduction over the whole frequency range. The dielectric response of EVA/CB5\% exhibited high frequencyindependent dielectric losses, so-called flat dielectric loss behavior [35], accompanied by a noticeable increase of the real permittivity. This is quite an intriguing result, since flat dielectric loss behavior normally occurs for low loss material (such as neat polyethylene or polypropylene). A possible explanation relates to the wide distribution of interfacial relaxation mechanisms due to the wide distribution of agglomerate size and morphology [36]. This would lead to a dielectric response consisting of the superposition of a large number of Debye-type relaxation processes with a broad distribution of relaxation times. The superposition of the relaxation peaks in dielectric losses would result in a negligible change of maximum one decade over the whole frequency range. At low filler concentration, below the percolation threshold, the EVA composites remained an insulating material with an AC conductivity in the vicinity of $10^{-15} \mathrm{~S} / \mathrm{m}$ at $0.01 \mathrm{~Hz}$, as shown in the inset. When the concentration is increased above the percolation threshold, the conductivity sharply increases, as explained by the percolation theory [26, 37-40] for which the conductivity can be expressed by $[26,41,42]$

$$
\sigma_{D C}=k\left(\varphi-\varphi_{c}\right)^{t}
$$

(Equation 4)

where $\mathrm{k}$ is a constant quantity, $\mathrm{t}$ is the critical exponent, $\varphi$ is the volume filler concentration and $\varphi_{c}$ is the volume concentration at critical concentration [41]. The direct current (DC) conductivity is not equivalent to the alternating current (AC) conductivity, shown in the inset for nonconductive samples, the DC conductivity being typically lower than the lowest value of the AC conductivity (the one at $0.01 \mathrm{~Hz}$ ). However, it is convenient to use the AC conductivity, as it can be readily measured both for conductive and insulating samples and this value converges on the value of the DC conductivity as soon as the material starts to become slightly conductive. Using the values of 
the AC conductivity at $0.01 \mathrm{~Hz}$, it can be seen that the electrical conductivity increases by 10 orders of magnitude when the conductive network starts to form (if the real values of the DC conductivity had been used instead, this increase would have been even larger). The conductive network in the EVA composites containing CB formed at lower filler concentration than for EVA with graphene. The reason might be related to the smaller size of CB (nano-sized) compared to the graphene (micro-sized) [43]. The other reason might be related to the formation of agglomeration of graphene during the composite fabrication [20, 44-46]; thus, a higher loading of graphene is needed to achieve a percolating network [14]. To understand the effect of processing conditions on the electrical conductivity of the composites, the dielectric properties of EVA/G15\% SM were also studied with the same frequency-domain type of measurement. Surprisingly, this investigation revealed a non-conductive composite, whereas the equivalent solvent-cast sample was found to be conductive. The reason might be the interruption of the percolating network within the composite due to additional agglomeration induced by the melt compounding process $[47,48]$.

The dielectric responses of the pure EVA, EVA/CB5\% and EVA/G15 \% were also assessed over the same range of frequencies at different temperatures, and the results are shown in Figure 5 in terms of three-dimensional plots of the imaginary permittivity as a function of frequency and temperature. The pure EVA revealed its two main relaxation peaks (Figure 5a). The sub-glassy peak is conventionally called the $\beta$-relaxation process. This appears at low temperature around 1 $\mathrm{kHz}$ and it is linked to the micro-Brownian motions of the acetate side groups [49]. As the temperature increased, the $\beta$-relaxation shifted toward the higher frequencies and merged with the $\alpha$ relaxation peak. This polarization mechanism is the main polarization phenomenon in EVA, and originates from reorientation of dipoles due to the segmental motion of the main chains [49, 50]. Scanning the dielectric response of the EVA polymer at higher temperatures (near the melting point) reveals a significant increase of dielectric loss at low frequency. This sharp increase of dielectric loss is due to the contribution of the charge carrier, leading to low frequency dispersion [35] with some possible contribution from ionic impurities creating electrode polarization. The dielectric loss of the EVA/CB5\% composite (Figure 5b) at different temperatures and frequencies revealed almost constant values for which the losses are not particularly low. This type of behavior has also been reported for ferroelectric materials and p-n junction [35], but its physical origins are not well understood. It seems that sub-percolating material might be another class of material exhibiting this behavior. Despite the global increase of the losses, it was still possible to observe 
both $\alpha$ and $\beta$ relaxation mechanisms, as well as the contribution from charge carriers. The addition of $15 \mathrm{wt} \%$ of graphene to pure EVA leads to a dielectric response dominated by the DC conductivity for the whole temperature and frequency range, as shown in Figure 5c.

\subsection{DSC and TGA results}

The role of $\mathrm{CB}$ and graphene fillers on the thermal properties of the EVA composites was investigated by differential scanning calorimetry (DSC). The obtained results are presented in Table II. The melting point, the degree of crystallinity and the lamellar thickness of the EVA composites including CB additive or graphene flakes were not found to change significantly with respect to the pure EVA copolymer. These results are in line with those recently reported [16, 25, $51,52]$.

Table II. Thermal properties and the lamellar thickness of EVA composites comprising CB and graphene fillers.

\begin{tabular}{lrcc}
\hline Samples & Melting point ${ }^{\circ} \mathrm{C}$ & Crystallinity (\%) & Lamellar thickness ( nm) \\
\hline Pure EVA & 87.0 & 20.4 & 4.40 \\
EVA/CB5\% & 87.2 & 20.3 & 4.42 \\
EVA/CB7\% & 87.4 & 20.7 & 4.30 \\
EVA/CB10\% & 87.8 & 20.5 & 4.43 \\
EVA/G10\% & 87.2 & 19.4 & 4.42 \\
EVA/G15\% & 87.3 & 19.6 & 4.42 \\
EVA/G15\%SM & 87.3 & 19.5 & 4.41 \\
\hline
\end{tabular}

Figures $6 \mathrm{a}$ and $6 \mathrm{~b}$ show the TGA thermograms and derivative thermal analysis (DTA) of the pure EVA and EVA composites with $\mathrm{CB}$ and graphene for temperatures from $200{ }^{\circ} \mathrm{C}$ to $600{ }^{\circ} \mathrm{C}$. The results show two stepwise thermal degradations of the specimens. As can be seen, the first onset of degradation started from approximately $300{ }^{\circ} \mathrm{C}$. This weight loss is related to the deacetylation process $[8,14,27]$ in which almost $10 \mathrm{wt} \%$ loss was seen for all specimens (losing acid acetic). The second weight loss starting from $450{ }^{\circ} \mathrm{C}$ corresponds to the degradation of the backbone chain $\left(\mathrm{CH}_{2}\right.$ groups) in EVA polymer [14, 53-55]. The addition of $\mathrm{CB}$ and graphene did not significantly increase the thermal endurance of the fabricated composites. The amount of remaining ash at $550{ }^{\circ} \mathrm{C}$ is given in Table III. The obtained values were in good agreement with the labeled filler content. 
Table III. TGA data, T onset at first and second degradation and ash content.

\begin{tabular}{lccc}
\hline Sample name & $\mathrm{T}_{-10 \%}\left({ }^{\circ} \mathrm{C}\right)$ & $\mathrm{T}_{-50 \%}\left({ }^{\circ} \mathrm{C}\right)$ & Ash content at $550^{\circ} \mathrm{C}$ \\
\hline Pure EVA & 381 & 482 & 0.20 \\
EVA/CB5\% & 382 & 483 & 4.30 \\
EVA/CB7\% & 384 & 483 & 7.30 \\
EVA/CB10\% & 384 & 486 & 10.1 \\
EVA/G10\% & 385 & 481 & 9.30 \\
EVA/G15\% & 384 & 486 & 13.8 \\
EVA/G15\% SM & 385 & 488 & 13.9 \\
\hline
\end{tabular}

\subsection{Mechanical properties}

The mechanical properties of the EVA composites, such as storage modulus (Figure 7a), loss modulus (Figure 7b), and $\tan \delta$ (inset in Figure 7b), were obtained by dynamic mechanical analysis over a wide range of temperature. The addition of graphene and CB fillers to the EVA copolymer was found to increase both dynamic mechanical properties (storage and loss modulus) over the entire glassy and rubbery regions of the composites. The rise of mechanical properties corresponded to the incorporation of filler in composite structure and possible physical contact between filler parts [56]. A drastic reduction in the storage modulus was found as an increase in the temperature occurred from $-50{ }^{\circ} \mathrm{C}$ to $0{ }^{\circ} \mathrm{C}$. This can be explained by the EVA transition from glassy to the rubbery state [27] . Corresponding to this drop in the modulus, an obvious peak was seen around $-20{ }^{\circ} \mathrm{C}$ in the $\tan \delta$ versus temperature graphs. Another peak at higher temperatures $\left(20-40^{\circ} \mathrm{C}\right.$ ) was observed in the tan $\delta$ curve, which represents the vanishing of the crystalline parts of the polyethylene as the hardest part in the composite $[8,40,57]$. Less area under the tan $\delta$ curve for the EVA/CB composites with respect to the EVA/G composites corroborates with better filler dispersion of the CB filler [26]. Additionally, the movement of the second peak in tan $\delta$ toward higher temperatures suggests suitable particle dispersion within the matrix [58].

\subsection{Thermal conductivity}

The thermal conductivity of the pure EVA and EVA composites with CB and graphene are shown in Figure 8. The thermal conductivity of all composites was found to increase with addition of conductive particles thanks to the large thermal conductivity of particles $[28,59,60]$. The mechanisms of thermal conduction in the composites are linked to the degree of crystallinity, the 
concentration of the particles, their size and shape [61, 62], their thermal conductivity, as well as the polymer matrix and processing conditions $[28,63]$. Thus, since significant change did not occur in the crystallinity of composites, the determining factor is the parameters related to the fillers. The reduction of the thermal conductivity for the extruded EVA composite (EVA/G15\% SM) compared with the non-extruded one (EVA/G15) can be explained by the interruption of the conducting network within the composite formed by solvent-casting due to the shear forces from fabrication, thus reducing the contribution from the electronic conduction to the thermal conduction process. Another factor that influences the thermal conductivity is the thermal interface resistance within the composite; as long as the uniform network within the composite is discontinuous, the number of separated individual particles is increased and, consequently, the value of interface resistance between particles and host polymer will grow and cause phonon scattering or even phonon backscattering $[64,65]$.

\section{Conclusions}

The electrical properties of EVA composites containing carbonaceous additives demonstrated significant dependency on the type of the conductive additive as well as the manufacturing method. Mechanical properties were also found to be affected by the fabrication process. The percolation

threshold for EVA composites with CB was found to be lower than for EVA composites containing graphene. Below the percolation threshold, the composites exhibited a high constant loss behavior that is also observed for different classes of dielectric. The onset of the melting temperature as well as the crystallization point was not significantly affected by the filler content. The same observation was made for thermal degradation temperatures that were not significantly affected by the addition of the conductive fillers. The composites of EVA containing CB and graphene additives showed slightly higher thermal conductivity than pure EVA. Analysis of electrical and thermal conductivity suggests that the dispersion, distribution and orientation of the filler strongly impact the above-mentioned properties.

\section{Acknowledgment}

The authors thank Natural Sciences and Engineering Research Council of Canada for the financial support.

\section{References}


[1] A.M. Henderson, Ethylene-vinyl acetate (EVA) copolymers: a general review, IEEE Electrical Insulation Magazine, 9 (1993), 30-38.

[2] M. Shafiee, S. Ramazani, Investigation of barrier properties of poly (ethylene vinyl acetate)/organoclay nanocomposite films prepared by phase inversion method, Macromolecular symposia, Wiley Online Library, 2008, pp. 1-5.

[3] Q. Wang, Q. Meng, T. Wang, W. Guo, High-performance antistatic ethylene-vinyl acetate copolymer/high-density polyethylene composites with graphene nanoplatelets coated by polyaniline, Journal of Applied Polymer Science, 134 (2017).

[4] X. Wang, B. Bi, J. Liu, S. Yang, L. Zhou, L. Lu, Y. Wang, F. Xu, R. Huang, Halogen-free intumescent flame-retardant ethylene-vinyl acetate copolymer system based on organic montmorillonite and graphene nanosheets, Journal of Applied Polymer Science, 135 (2018), 46361 .

[5] S. Sheng, S. Liu, L. Zhang, G. Chen, Graphene/poly (ethylene-co-vinyl acetate) composite electrode fabricated by melt compounding for capillary electrophoretic determination of flavones in Cacumen platycladi, Journal of separation science, 36 (2013), 721-728.

[6] P.S. Khobragade, D. Hansora, J.B. Naik, J. Njuguna, S. Mishra, Effect of multilayered nanostructures on the physico-mechanical properties of ethylene vinyl acetate-based hybrid nanocomposites, Polymer Composites, (2017).

[7] H. Tang, Z. Liu, J. Piao, X. Chen, Y. Lou, S. Li, Electrical behavior of carbon black-filled polymer composites: Effect of interaction between filler and matrix, Journal of applied polymer science, 51 (1994), 1159-1164.

[8] T. Kuila, P. Khanra, A.K. Mishra, N.H. Kim, J.H. Lee, Functionalized-graphene/ethylene vinyl acetate co-polymer composites for improved mechanical and thermal properties, Polymer Testing, 31 (2012), 282-289.

[9] Y.H. Hou, M.Q. Zhang, M.Z. Rong, G. Yu, H.M. Zeng, Improvement of conductive network quality in carbon black-filled polymer blends, Journal of applied polymer science, 84 (2002), 2768-2775.

[10] Y.H. Hou, M.Q. Zhang, M.Z. Rong, Performance stabilization of conductive polymer composites, Journal of applied polymer science, 89 (2003), 2438-2445. 
[11] G. Takidis, D. Bikiaris, G. Papageorgiou, D. Achilias, I. Sideridou, Compatibility of lowdensity polyethylene/poly (ethylene-co-vinyl acetate) binary blends prepared by melt mixing, Journal of applied polymer science, 90 (2003), 841-852.

[12] M. Çopuroğlu, M. Şen, A comparative study of UV aging characteristics of poly (ethyleneco-vinyl acetate) and poly (ethylene-co-vinyl acetate)/carbon black mixture, Polymers for advanced technologies, 16 (2005), 61-66.

[13] J. Jyoti, A. Kumar, S. Dhakate, B.P. Singh, Dielectric and impedance properties of three dimension graphene oxide-carbon nanotube acrylonitrile butadiene styrene hybrid composites, Polymer Testing, 68 (2018), 456-466.

[14] N. Yuan, F. Ma, Y. Fan, Y. Liu, J. Ding, High conductive ethylene vinyl acetate composites filled with reduced graphene oxide and polyaniline, Composites Part A: Applied Science and Manufacturing, 43 (2012), 2183-2188.

[15] K.F. Ratzsch, V. Cecen, F. Tölle, K.A. Wartig, R. Thomann, R. Mülhaupt, C. Friedrich, Rheology, Electrical Properties, and Percolation of TRGO-Filled EVA-Copolymers, Macromolecular Materials and Engineering, 299 (2014), 1134-1144.

[16] Q.Q. Yang, J.Z. Liang, Electrical properties and morphology of carbon black-filled HDPE/EVA composites, Journal of applied polymer science, 117 (2010), 1998-2002.

[17] J.J. George, S. Bhadra, A.K. Bhowmick, Influence of carbon-based nanofillers on the electrical and dielectric properties of ethylene vinyl acetate nanocomposites, Polymer Composites, 31 (2010), 218-225.

[18] M. Azizi, S.A. Ramazani, M.H. Etemadi, S.E. Shirzaei, Simulation of viscoelastic fluid flows in expansion geometry using finite volume approach, Chinese Journal of Polymer Science, 31 (2013), 1599-1612.

[19] Z. Boussaboun, S. Azizi, C. Ouellet-Plamondon, Conductive clay containing graphene layers, Nanotechnology (IEEE-NANO), 2017 IEEE 17th International Conference on, IEEE, 2017, pp. 1065-1069.

[20] M. Soheilmoghaddam, H. Adelnia, H.C. Bidsorkhi, G. Sharifzadeh, M.U. Wahit, N.I. Akos, A.A. Yussuf, Development of Ethylene-Vinyl Acetate Composites Reinforced with Graphene Platelets, Macromolecular Materials and Engineering, 302 (2017). 
[21] R.S. Kurusu, E. Helal, N. Moghimian, E. David, N. Demarquette, The Role of Selectively Located Commercial Graphene Nanoplatelets in the Electrical Properties, Morphology, and Stability of EVA/LLDPE Blends, Macromolecular Materials and Engineering, (2018), 1800187. [22] R. Méndez, B. Constant, C. Garzon, M. Nisar, S.M.B. Nachtigall, R. Quijada, Barrier, mechanical and conductive properties of polycaprolactam nanocomposites containing carbonbased particles: Effect of the kind of particle, Polymer, 130 (2017), 10-16.

[23] M. Azizi, A. Zolfaghari Sharak, S.A. Mousavi, F. Bakhtiari Ziabari, J. Shariati, S. Azizi, Study on the acetylene hydrogenation process for ethylene production: Simulation, modification, and optimization, Chemical Engineering Communications, 200 (2013), 863-877.

[24] S.R. Pajoumshariati, M. Azizi, D. Wesner, P.G. Miller, M.L. Shuler, A. Abbaspourrad, Microfluidic-Based Cell-Embedded Microgels Using Nonfluorinated Oil as a Model for the Gastrointestinal Niche, ACS applied materials \& interfaces, 10 (2018), 9235-9246.

[25] S. Pu, Y.-B. Hao, X.-X. Dai, P.-P. Zhang, J.-B. Zeng, M. Wang, Morphological, rheological, crystalline and mechanical properties of ethylene-vinyl acetate copolymer/linear low-density polyethylene/amphiphilic graphene oxide nanocomposites, Polymer Testing, 63 (2017), 289-297.

[26] O. Yousefzade, F. Hemmati, H. Garmabi, M. Mahdavi, Thermal behavior and electrical conductivity of ethylene vinyl acetate copolymer/expanded graphite nanocomposites: Effects of nanofiller size and loading, Journal of Vinyl and Additive Technology, 22 (2016), 51-60.

[27] A. Badiee, I.A. Ashcroft, R.D. Wildman, The thermo-mechanical degradation of ethylene vinyl acetate used as a solar panel adhesive and encapsulant, International Journal of Adhesion and Adhesives, 68 (2016), 212-218.

[28] J.S. Sefadi, A.S. Luyt, J. Pionteck, F. Piana, U. Gohs, Effect of surfactant and electron treatment on the electrical and thermal conductivity as well as thermal and mechanical properties of ethylene vinyl acetate/expanded graphite composites, Journal of Applied Polymer Science, 132 (2015).

[29] R. Kochetov, T. Andritsch, P.H.F. Morshuis, J.J. Smit, Anomalous Behaviour of the Dielectric Spectroscopy Response of Nanocomposites, Ieee Transactions on Dielectrics and Electrical Insulation, 19 (2012), 107-117. 
[30] K. Gaska, X. Xu, S. Gubanski, R. Kádár, Electrical, Mechanical, and Thermal Properties of LDPE Graphene Nanoplatelets Composites Produced by Means of Melt Extrusion Process, Polymers, 9 (2017), 11.

[31] X. Shi, J. Zhang, J. Jin, S. Chen, Non-isothermal crystallization and melting of ethylenevinyl acetate copolymers with different vinyl acetate contents, Express Polym Lett, 2 (2008), 623-629.

[32] P. Gill, T.T. Moghadam, B. Ranjbar, Differential scanning calorimetry techniques:

applications in biology and nanoscience, Journal of biomolecular techniques: JBT, 21 (2010), 167.

[33] Y. Furushima, M. Nakada, M. Murakami, T. Yamane, A. Toda, C. Schick, Method for calculation of the lamellar thickness distribution of not-reorganized linear polyethylene using fast scanning calorimetry in heating, Macromolecules, 48 (2015), 8831-8837.

[34] S. Azizi, C. Ouellet-Plamondon, E. David, M. Fréchette, Electrical and thermal properties of low-density polyethylene/graphene-like composite, Electrical Insulation and Dielectric Phenomenon (CEIDP), 2017 IEEE Conference on, IEEE, 2017, pp. 517-520.

[35] A.K. Jonscher, Dielectric relaxation in solids, Journal of Physics D: Applied Physics, 32 (1999), R57.

[36] L.A. Utracki, C.A. Wilkie, Polymer blends handbook, Springer2002.

[37] X. Huang, C. Zhi, Polymer Nanocomposites, (2016).

[38] K.K. Sadasivuni, D. Ponnamma, J. Kim, S. Thomas, Graphene-based polymer nanocomposites in electronics, Springer2015.

[39] S.B. Kondawar, Conducting Polymer Nanocomposites for Supercapacitors, Smithers Rapra2015.

[40] N. Das, T. Chaki, D. Khastgir, Effect of filler treatment and crosslinking on mechanical and dynamic mechanical properties and electrical conductivity of carbon black-filled ethylene-vinyl acetate copolymer composites, Journal of applied polymer science, 90 (2003), 2073-2082. [41] S. Mondal, L. Nayak, M. Rahaman, A. Aldalbahi, T.K. Chaki, D. Khastgir, N.C. Das, An effective strategy to enhance mechanical, electrical, and electromagnetic shielding effectiveness of chlorinated polyethylene-carbon nanofiber nanocomposites, Compos Part B-Eng, 109 (2017), 155-169. 
[42] R. Rizvi, H. Naguib, Effect of carbon nanoparticle type, content, and stress on piezoresistive polyethylene nanocomposites, Polym Eng Sci, 55 (2015), 1643-1651.

[43] U.B. Klaus Friedrich, Multifunctionality of Polymer Composites Challenges and New Solutions, Elsivier, (2014).

[44] E. Tkalya, Graphene-based polymer nanocomposites, PhD thesis, Technische Universiteit Eindhoven (Eindhoven), 2012.

[45] K. Singh, A. Ohlan, S. Dhawan, Polymer-graphene nanocomposites: Preparation, characterization, properties, and applications, Nanocomposites-New Trends and Developments, InTech2012.

[46] Z.-M. Dang, J.-K. Yuan, J.-W. Zha, T. Zhou, S.-T. Li, G.-H. Hu, Fundamentals, processes and applications of high-permittivity polymer-matrix composites, Progress in Materials Science, 57 (2012), 660-723.

[47] S.C. Tjong, Y.-W. Mai, Physical properties and applications of polymer nanocomposites, Elsevier2010.

[48] F. Bellucci, D. Fabiani, G. Montanari, L. Testa, The processing of nanocomposites, Dielectric Polymer Nanocomposites, Springer2010, pp. 31-64.

[49] A. Alegria, J. Colmenero, Dielectric relaxation of polymers: segmental dynamics under structural constraints, Soft matter, 12 (2016), 7709-7725.

[50] G.G. Raju, Dielectrics in electric fields, CRC press2016.

[51] M. Bahmanyar, A. Ramazani SA, H. Baniasadi, Preparation and Properties of Ethylenevinyl Acetate/linear Low-density Polyethylene/Graphene Oxide Nanocomposite Films, PolymerPlastics Technology and Engineering, 54 (2015), 1152-1158.

[52] B. Borisova, J. Kressler, Environmental Stress-Cracking Resistance of LDPE/EVA Blends, Macromolecular Materials and Engineering, 288 (2003), 509-515.

[53] M.C. Costache, D.D. Jiang, C.A. Wilkie, Thermal degradation of ethylene-vinyl acetate coplymer nanocomposites, Polymer, 46 (2005), 6947-6958.

[54] M. Sabet, H. Soleimani, S. Hosseini, Effect of addition graphene to ethylene vinyl acetate and low-density polyethylene, Journal of Vinyl and Additive Technology, 24 (2018), E177E185.

[55] H. Wu, W. Zhao, G. Chen, One-pot in situ ball milling preparation of polymer/graphene nanocomposites, Journal of Applied Polymer Science, 125 (2012), 3899-3903. 
[56] B. Mensah, K.C. Gupta, H. Kim, W. Wang, K.-U. Jeong, C. Nah, Graphene-reinforced elastomeric nanocomposites: A review, Polymer Testing, 68 (2018), 160-184.

[57] J. Jacob George, A. Bandyopadhyay, A.K. Bhowmick, New generation layered nanocomposites derived from ethylene-co-vinyl acetate and naturally occurring graphite, Journal of applied polymer science, 108 (2008), 1603-1616.

[58] W. Stark, M. Jaunich, Investigation of ethylene/vinyl acetate copolymer (EVA) by thermal analysis DSC and DMA, Polymer Testing, 30 (2011), 236-242.

[59] J.J. George, A.K. Bhowmick, Ethylene vinyl acetate/expanded graphite nanocomposites by solution intercalation: preparation, characterization and properties, Journal of materials science, 43 (2008), 702-708.

[60] J. George, A.K. Bhowmick, Fabrication and properties of ethylene vinyl acetate-carbon nanofiber nanocomposites, Nanoscale research letters, 3 (2008), 508.

[61] H.S. Kim, H.S. Bae, J. Yu, S.Y. Kim, Thermal conductivity of polymer composites with the geometrical characteristics of graphene nanoplatelets, Scientific reports, 6 (2016), 26825.

[62] X. Wang, Y. Zhao, J. Jin, M. Song, A comparative study on the effect of carbon fillers on electrical and thermal conductivity of a cyanate ester resin, Polymer Testing, 60 (2017), 293-298. [63] S. Ghose, K.A. Watson, D.C. Working, J.W. Connell, J.G. Smith, Y.P. Sun, Thermal conductivity of ethylene vinyl acetate copolymer/nanofiller blends, Composites Science and Technology, 68 (2008), 1843-1853.

[64] X. Sun, P. Ramesh, M.E. Itkis, E. Bekyarova, R.C. Haddon, Dependence of the thermal conductivity of two-dimensional graphite nanoplatelet-based composites on the nanoparticle size distribution, Journal of Physics: Condensed Matter, 22 (2010), 334216.

[65] N. Burger, A. Laachachi, M. Ferriol, M. Lutz, V. Toniazzo, D. Ruch, Review of thermal conductivity in composites: mechanisms, parameters and theory, Progress in Polymer Science, 61 (2016), 1-28. 